\title{
Environmental migration and sustainable development of regions and countries
}

\author{
Irina Reznikova ${ }^{1 *}$, Natalya Danilina ${ }^{1}$ \\ ${ }^{1}$ Institute of Engineering and Environmental Security, Togliatti State University, Belorusskaya str. 14, \\ 445020 Togliatti, Russian Federation
}

\begin{abstract}
Our paper focuses on studying the development and implementation of a comprehensive environmental safety assessment and mitigation strategy for countries of origin and destination of environmental migration. Environmental migration represents one of the key threats to the security of regions and countries and is linked to their sustainable development (or lack thereof). Moreover, it is also connected to many important social, economic as well as demographic outcomes. Global warming caused by human activities is already having a major impact on the planet and is likely to render parts of the world uninhabitable, leading to migration, displacement, and planned resettlement. The goal of the paper is also to assess the impact of future migration due to the global warming and climate change. The results of the paper demonstrate that climate impacts can trigger migration and change population distribution within the next few decades. It is also clear that migration caused by the environmental factors (such as droughts, floods, higher temperature sand more extreme weather events) would inevitably lead to the geopolitical changes with long-range impacts and effects.
\end{abstract}

\section{Introduction}

While understanding that there is a link between the climate factors and environmental migration is helpful, there is a lack of information on how exactly and in what wat they affect migration [1]. On the migration side, researchers have uncovered so-called "stylized facts" that govern how and why people move and under what circumstances for more than a century. These changes include increased droughts, more frequent floods, higher temperatures and more extreme weather events, and changes that threaten well-being - the very existence and livelihood of the people [2]. People who are severely affected by changing ecological conditions can choose to emigrate from their home countries. Some people fleeing pollution may be identified as climate refugees, and some who want to emigrate may seek refuge in other countries less affected by climate extremes. People who are severely affected by changes in the ecological state, such as people in Africa, Asia, Latin America or the Middle East, may choose to move to other parts of the world or even to their own countries. Some international refugee organizations, including the United Nations, prefer the term "environmental migrants" [3].

\footnotetext{
* Corresponding author: IVReznikova@yandex.ru
} 
Under the Immigration and Nationality Act, a refugee is defined as "a person who cannot or does not want to return to their home country due to a well-founded fear of persecution" [4]. Climate migrants would also have to make the argument that their home country's government could not protect them when they returned. Some could potentially be considered members of certain social groups, such as refugees, asylum seekers and war refugees. This is because some countries such as the United States has no clear path to help climate migrants, owing to the few legal provisions. Most of the research on climate migration has been conducted in developing countries, and one reason that there has been less focus on the issues in developed countries is that their populations are highly urbanized, and that people's incomes and livelihoods are less dependent on local environmental conditions, owing to expanded international supply chains [5].

Nevertheless, there is a growing interest in the management of sanctuary areas and climate control - exposed areas in developing countries, particularly in the Middle East and North Africa. It is important to understand local planning needs and how existing government policies on the management of protected areas and climate protection areas - exposed areas can best be changed [6]. The Paris Agreement of 2016 also takes note of migration and aims to set up a working group to draw up recommendations.

One can see that environmental refugees as an emerging security problem and addressing the problem by establishing a framework for identifying environmental forced migration as a threat to national security. In order to tackle that, many countries adopted a conceptual approach to the integration of immigrants involving a wide range of actors, including nongovernmental organisations, and has further promoted the development of an open-door immigration policy for immigrants and their families [7]. There are negative aspects of international migration that can lead to security threats, such as insufficient integration of legal migrants, which can lead to social tensions that can lead to the displacement of people belonging to immigrants. Political instability, poverty and climate change are caused by uncontrolled mass migration, and this needs to be addressed in the face of an ageing population.

\section{Natural and environmental disasters}

As the name suggests, it is a disaster that damages property and affects the people, flora and fauna around it. Natural disasters are essentially sudden events caused by changing environmental patterns due to human activities such as climate change or natural disasters [8]. In extreme cases, they can be extreme in terms of death, environmental damage and property destruction.

Environmental disasters always occur when the balance of the environment is disturbed. The worst thing is that they can strike anytime and anywhere on the earth without warning and strike at any time of the day or night [9]. The turbulence caused by rough sewage silts the water, causing less sunlight to enter, which affects the amount of photosynthesis, leading to a decrease in dissolved oxygen. Strong winds in the ocean increase nutrients in certain areas due to a process that brings nutrient-rich water to the surface. Hurricane Sandy in 2012 was one of the most devastating storms to hit Connecticut's power grid, causing 15,000 power outages that affected more than 500,000 customers. The damage to energy infrastructure was so severe that power outages occurred in areas of New York and New Jersey, and in the months following the storm, power was not restored in those areas or in the areas of New York and New Jersey [10]. A record storm surge from Hurricane Sandy has hit the north-eastern United States, causing an estimated 11 billion gallons of partially treated sewage to spill into the Atlantic Ocean, posing a threat to the environment and health. Another example is California which has always been vulnerable to wildfires that burn and destroy power lines and cause severe damage to the state's energy infrastructure. But in the 
past two years, major wildfires in California have also destroyed thousands of buildings, forced hundreds of thousands to evacuate their homes, and killed at least 44 people nationwide. Climate change is exacerbating natural disasters such as forest fires and floods, making them more frequent and severe [11]. The Intergovernmental Panel on Climate Change (IPCC) has described in detail the predicted effects of climate change on the state of California and the United States [12]. Many climatic stresses that carry risks, especially associated with dwindling snowpack, increased the risk of extreme weather events such as floods, droughts and wildfires in California. As the world warms, the cost to Americans may also justify the need to adapt to the damage caused by climate change.

Many scientists are increasingly investigating the role that climate change plays in certain disasters. Although many factors have contributed to these weather events, scientists agree that climate change generally leads to, and will continue to lead to, more frequent, severe, and damaging extreme event. Since vulnerability is the determining factor in the impact of disasters, we argue that humanity's development models have also contributed significantly to the disasters that have occurred [13]. The increase in the socio-economic aspects of disasters shows a $3 \%$ increase in the numbers, with a direct impact on vulnerable communities. Social capital, which is linked to social and economic structures, has a significant impact as a factor that reduces the vulnerability of affected communities and contributes to the environmental impact of disasters. Natural disasters are caused by a number of factors, such as climate change, natural disasters and human activities, which have a negative impact on the natural and built-up environment in the affected region [14]. Such decisions, combined with a lack of awareness of the environmental impact of human activities and their impact on the environment, provoke a number of socio-economic and environmental impacts. The negative environmental impacts of storms and typhoons are increasing every year, leading to an increase in the number of natural disasters such as floods, droughts, hurricanes, typhoons and cyclones. For example, not all disasters have a significant impact on the environment; many earthquakes have only a small impact on ecosystems, and extreme climate events can have a positive impact on the local environment. Flooding can help rejuvenate floodplains and vegetation, but pollutants from flooded industrial plants can lead to dangerous chemicals entering project areas, groundwater, watersheds and oceans untreated.

\section{Environmental problems and their effects on human lives}

Environmental problems surely have significant effects on human lives. These effects could threaten human health by affecting the food we eat, the water we drink, the air we breathe and the weather we experience. The severity of health risks will depend on the capacity of public health and security systems to respond and prepare to these evolving threats. These impacts will vary depending on where a person lives, how sensitive they are to health threats, how exposed they are to the effects of climate change, or how well they and their communities can adapt to these changes [15]. People in developing countries may be the most vulnerable to health risks worldwide, but climate change poses a significant threat to our health. Current weather variations are already having a negative impact on health in many developing countries, such as Africa, Asia and the Middle East. Climate change is exacerbating existing and often enormous health problems, especially in poorer parts of the world. There is also the potential to multiply the additional stress from climate change from the effects of extreme weather events such as floods, droughts and extreme heat waves [16]. In fact, improved health is often the result of transforming natural ecosystems into expanded agriculture to improve access to food and water. Degradation of a particular ecosystem can lead to deforestation, leading to increased malaria exposure and biodiversity loss. 
Climate change is affecting not only the health of people in the United States, but also many other countries around the world. A warmer, more variable climate will lead to higher levels of air pollution [17]. There are currently limits on the amount of carbon dioxide $\left(\mathrm{CO}_{2}\right)$ and other greenhouse gases in the atmosphere. Human health and well-being are inextricably linked to the quality of the environment and it is increasingly recognised that human exposure to high levels of air, water and other pollution is associated with a number of harmful health effects. It is increasingly recognised that linking environmental and health impacts requires economic assessment in order to ensure that they are properly reflected in policy [18].

Consequently, in recent years we have seen a wave of assessment studies that seek to quantify the environmental impact on human health in monetary terms and to find evidence that health and environmental policies reduce the risk of disease and death. We therefore believe that the use of various tools in assessing the health effects of environmental policy in the context of the global threat to human life and well-being posed by climate change should be improved [19]. A subsequent section presents the assessment techniques that have been carried out to assess the social benefits of improved air and water quality. A more robust approach to assessing the net impact of such changes on health would have a significant impact on policy decisions on health and well-being - and would be seen in the context of climate change.

In many parts of the world, there are additional health impacts that interact with the effects of climate change, such as changes in air and water quality, food security and pollution. Environmental health professionals need to study how people interact with the world around them, and record the many ways in which these interactions can affect health and well-being, as well as the health of their families and communities. One of the challenges is to assess the impact of environmental problems on the long-term impact of these changes on human health. Maintaining a healthy environment is crucial to helping people live longer and improve their quality of life. Understanding the distribution and concentration of pollutants in the environment increases our ability to understand the role of these hazards to human health and to develop ways to remain healthier [20]. By improving environmental health, public health professionals can also improve the personal well-being of people in their communities and their families. The system is tracking network uses data from many sources to track the effects of climate change. Although there are a number of indicators related to climate change, the tracking network has had data on extreme heat and flood vulnerability for more than 20 years. As pollution from climate change increases worldwide, diseases caused by environmental factors are on the rise, and doctors are increasingly warning people of the growing health consequences. The World Health Organization and the United Nations have called on countries to restore the environment and aggressively curb greenhouse gas emissions in order to protect human health.

\section{Social phenomena of environmental migration}

The world has a growing population and mobility, with the dominant flow of people over the past decade moving from the countryside to the cities. Migration is therefore an important part of the social phenomenon of ecological migration and a key element of economic development [21]. At the same time, the world is in the midst of one of the most intense periods of climate change in human history. However, we have failed to take systematic account of the social consequences of people moving from one place to another and the environmental risks that arise. The researchers link the issue of environmental change to human migration and explicitly refer to people forced to leave their homes as "environmental refugees" [22].

Although environmental studies have traditionally focused on the natural world, there is little research on the social impact of environmental change on human health and well-being. 
The effects of many of these processes have been considered catastrophic, because they create stress, disrupt normal social processes, force people to adapt, and make changes in the way they do things in life.

Most countries experience a form of migration that involves forced immobility, and in which the population is ultimately trapped. The slow onset of natural and human environmental change in the world rarely directly or linear influences migration drivers and patterns. Where the environmental component is nevertheless crucial, itis often embedded and difficult to identify. Research on this current issue has improved considerably, but there are still gaps in quantitative data. To investigate whether women are more vulnerable because of their lower education level, detailed empirical research is needed. We reject the idea that higher levels of education increase the propensity to migrate and thus the risk of environmental migration. Therefore, the factors that determine the impact of environmental factors on migration, such as climate change, must be taken into account, as social, cultural, economic and political aspects interact with the environmental factor. Sceptics on both sides tend to question models of sea-level rise as simplistic, explaining that the decision to migrate is complex and includes factors such as economic, social, cultural, political, and environmental factors. They have a migrant background and humanitarian background, and worry about the potential backlash against migrants, given the alarming predictions of millions of people who are fleeing.

Some migration experts are concerned about whether the term "refugee" has a precise meaning under international law. The appeal argues that a million people loosely referred to as refugees will devalue the legally recognized concept of refugees at a time when some 15 million people are desperately seeking protection from violence and conflict. For this reason, climate migration is often associated with the term "refugee," a legal category that is limited to people fleeing persecution because of factors such as race, ethnicity, religion, nationality, or political affiliation [23]. As for will, environmental migration is generally thought to fall at the forced end of the spectrum. The three dimensions of migration include the distance travelled, the number of migrants crossing borders and their ability to stay or remain. For example, in the case of climate migration, the number of migrants in response to climate change is increasing, but not in proportion to the extent of change. Many scientists describe migration as a social phenomenon in which environmental factors such as climate change can trigger a first surge in migration. In other words, people's ability to adapt to environmental change, not the nature of migration itself, may be the most important factor in climate - induced migration [24].

While climate impacts challenge the notion that climate change will directly lead to migration, they could reinforce existing social vulnerabilities. Although the underlying causes of vulnerability have little to do with why people end up moving, there can be sociopolitical and economic causes. Thence, the underlying social vulnerabilities could determine whether individuals and communities can enjoy the luxury of migration. But then the underlying social vulnerability determines whether an individual or community can avail itself of this luxury to migrate, and if so, when. The IPCC synthesis report articulates climate change as a real and looming problem, but others doubt that the focus on environmental migration is an attempt to see the phenomenon as capable of translating into financial risk [25]. Most striking, however, is that the focus on migration as an economic and social risk factor for the global economy has been much discussed in recent years. This suggests that, without a significant climate-change effort, the world is trapped in an environment whose impacts are unequally spread in speed and scale, both in the social and environmental areas of climate change. 


\section{Conclusions}

This paper assessed the impact of future migration due to climate change by providing the summary of key lessons and evidence. The paper made it clear that global environmental changes could affect the movement of the world's population.

While economic, social, and political factors influence migration, environmental changes also affect it in other ways. Migration associated with environmental decline is usually characterized by short-term distant and long-term movements. However, due to the breadth and complexity of interactions between drivers, it will rarely be possible to distinguish between individuals for whom environmental factors are the only driver. However, if the number of people at risk of migration due to environmental change increases significantly, very high numbers are unlikely to materialise. It is politically and ethically important that northern low-population countries are largely responsible for climate change, while southern high-population and high-growth countries have contributed very little to it. However, migrant groups are exposed to a number of stressors, including economic, social, political and environmental factors, as well as human rights concerns. Despite the serious concerns about human rights raised by the rapid increase in migration due to environmental change in recent years, there is still a need to discuss the population at government and international level. Where the environmental component is difficult to identify but crucial, migration drivers and patterns are influenced by the slow onset of natural and human environmental change. Most countries experience a form of migration that involves forced immobility and in which a population is trapped, and this is rarely direct or linear.

If we want our research to influence policy and provide information to decision-makers making climate-change mobility decisions, we propose that we face four dilemmas. Movements can occur immediately, for example in response to imminent floods, or they can occur in the wake of an event that ends with a long-term change in climate or other environmental conditions. Without a return to another area, communities and individuals may be temporarily displaced but return at the end of the event. Migrant destinations can also be influenced by historical migration patterns, where new migrants follow old routes. The reasons why people migrate or seek refuge can be complex, making it difficult to predict how climate change will affect future migration.

It is important to understand how climate change-driven migration differs from the motivations for human migration. Underestimating the extent to which climate change will affect human migration is therefore a decision - one that makes mistakes in the context of any country's national security and economic interests. A framework is needed that would recognize the imperfections of any given assessment of migration and allows us to think critically about the possible ways in which climate change can change migration patterns. This framework would have to assess the wider impact of climate change on populations by explicitly including populations directly affected by it and those indirectly affected by climate change- that is, migration and patterns of migration.

\section{References}

1. E. Piguet, R. Kaenzig, J. Guélat, Population and Environment, 39(4), 357-383 (2018)

2. D.J. Kaczan, J. Orgill-Meyer, Climatic Change, 158(3), 281-300 (2020)

3. UNHCR, https://www.unhcr.org/what-is-a-refugee.html (2021)

4. R. Sunam, K. Barney, J.F. McCarthy, Geoforum, 118, 1-13 (2021)

5. Z. Mencütek, Refugee Governance, State and Politics in the Middle East (2018)

6. P. Cajka, M. Jaroszewicz, W. Strielkowski, Economics and Sociology, 7(4), 11-25 (2014)

7. M.R. Islam, N.A. Khan, Journal of the Asia Pacific Economy, 23(2), 297-323 (2018) 
8. A. Blazev, Energy security for the $21^{\text {st }}$ century (2021)

9. E. Sharma, S. Das, International Journal of Environment and Waste Management, 25(3), 356-380 (2020)

10. Z. Liu, H. Wang, Y.J. Zhang, L. Magnusson, J.D. Loftis, D. Forrest, Coastal and Shelf Science, 233, 106544 (2020)

11. H. Moftakhari, A. Kouchak, Environmental Research Letters, 14(10), 104018 (2019)

12. T.B. Pathak, M.L. Maskey, J.A. Dahlberg, F. Kearns, K.M. Bali, D. Zaccaria, Agronomy, 8(3), 25 (2018)

13. S. Osaka, R. Bellamy, Global Environmental Change, 62, 102070 (2020)

14. S. Kim, S.A. Kwon, J.E. Lee, B.C. Ahn, J.H. Lee, C. An, K. Kitagawa, D. Kim, J. Wang, Sustainability, 12, 3377 (2020)

15. M. McKee, D. Stuckler, Nature Medicine, 26(5), 640-642 (2020)

16. M. Abdollahbeigi, Journal of Chemical Reviews, 2(4), 292-308 (2020)

17. W. Nordhaus, American Economic Review, 109(6), 1991-2014 (2019)

18. A.A. Almetwally, M. Bin-Jumah, A.A. Allam, Environmental Science and Pollution Research, 27(20), 24815-24830 (2020)

19. A. Caplin, M. Ghandehari, C. Lim, P. Glimcher, G. Thurston, Nature communications, 10(1), 1-11 (2019)

20. K. Hayes, G. Blashki, J. Wiseman, S. Burke, L. Reifels, International journal of mental health systems, 12(1), 1-12 (2018)

21. F. Castelli, Journal of travel medicine, 25(1), tay040 (2018)

22. K.F. Davis, A. Bhattachan, P. D’Odorico, S. Suweis, Environmental Research Letters, 13(6), 064030 (2018)

23. S. Wilmer, Performing statelessness in Europe (2018)

24. D. J. Kaczan, J. Orgill-Meyer, Climatic Change, 158(3), 281-300 (2020)

25. S. Behrman, A. Kent (eds.), Climate refugees: beyond the legal impasse? (2018) 